\title{
EVALUATION OF THE RELIABILITY OF THE 8-SECOND SKIPPING WITH HAND CLAPPING TEST IN 5- AND 6-YEAR-OLD KINDERGARTENERS WITH THE USE OF THE TEST-RETEST METHOD: METHODOLOGICAL ASPECTS AND PRACTICAL IMPLICATIONS
}

original paper

( ) University School of Physical Education in Wroclaw

DOI: https://doi.org/10.5114/hm.2018.76080

\section{ROBERT PODSTAWSKI ${ }^{1}$, STANISLAW KONOPKA ${ }^{2}$, DARIUSZ CHOSZCZ ${ }^{2}$, RAFAEL MERINO-MARBAN ${ }^{3}$, OSCAR ROMERO-RAMOS ${ }^{3}$, MILOS MARKOVIC $^{4}$, STANIMIR STOJILJKOVIC ${ }^{4}$}

\author{
${ }^{1}$ Department of Physical Education and Sport, University of Warmia and Mazury in Olsztyn, Olsztyn, Poland \\ ${ }^{2}$ Department of Heavy Duty Machines and Research Methodology, Faculty of Technical Sciences, \\ University of Warmia and Mazury in Olsztyn, Olsztyn, Poland \\ ${ }^{3}$ Faculty of Educational Sciences, University of Malaga, Malaga, Spain \\ ${ }^{4}$ Faculty of Sports and Physical Education, University of Belgrade, Belgrade, Serbia
}

\section{ABSTRACT}

Purpose. The aim of the study was to evaluate the reliability of the 8-s Skipping with Hand Clapping (8-s SHC) test performed by kindergarteners.

Methods. The study involved 60 girls and 57 boys (mean age: $67.80 \pm 9.00$ and $71.76 \pm 6.43$ months, respectively). The reliability of the 8-s SHC test was determined on the basis of the calculated values of correlation coefficients between the numbers of claps in 10 successive test trials. The 'training trend' hypothesis was verified by the Friedman test as well as Conover-Iman's post-hoc test, which was additionally used to identify the trials of the 8-s SHC test that differed significantly in the number of claps.

Results. The values of correlation coefficients between the numbers of claps in 10 successive trials of the 8-s SHC test were within the range from acceptable reliability (0.80-0.90) to perfect reliability (0.95-0.99) in both girls and boys. Statistically significant differences between the numbers of claps in successive trials point to the presence of a 'training trend.' Those differences were observed up to the $3^{\text {rd }}$ trial in boys and up to the $5^{\text {th }}$ trial in girls.

Conclusions. The 8-s SHC test can be reliably used to assess speed abilities among kindergarteners. The 'training trend' should be eliminated before the test is used to evaluate the speed abilities of preschool children. A minimum number of repetitions (19 in girls and 15 in boys) have to be performed in advance for the final test to deliver reliable results.

Key words: reliability assessment, retest method, training trend, speed abilities, 8-s SHC test, kindergarteners

\section{Introduction}

When evaluating the use of tests in physical fitness assessments, special attention should be paid to the fact that a given measurement can be a reliable indicator of the assessed motor ability only if it meets test adequacy criteria such as validity, reliability, objectivity, standardization, and normalization. According to other authors, the above list should be expanded to include time-effectiveness and cost-effectiveness [1-4].
The term 'reliability,' used interchangeably with 'repeatability, 'reproducibility,' 'agreement,' and 'stability' [5], can be defined as consistency of measurements [6]. The reliability of a test is related to the magnitude of error in the measurement process. In repeated measures motor tests, reliability represents the overall consistency of results [5, 7]. A reliable test produces identical or nearly identical results each time when the same individuals are tested under constant and invariable conditions [8]. The consistency of a measure

Correspondence address: Robert Podstawski, Department of Physical Education and Sport, University of Warmia and Mazury in Olsztyn, Prawocheńskiego 7, 10-720 Olsztyn, Poland, e-mail: podstawskirobert@gmail.com

Received: January 26, 2018

Accepted for publication: April 26, 2018

Citation: Podstawski R, Konopka S, Choszcz D, Merino-Marban R, Romero-Ramos O, Markovic M, Stojiljkovic S. Evaluation of the reliability of the 8-second skipping with hand clapping test in 5- and 6-year-old kindergarteners with the use of the test-retest method: methodological aspects and practical implications. Hum Mov. 2018;19(3):55-63; doi: https://doi. org/10.5114/hm.2018.76080. 
can be expressed as the reliability coefficient. The reliability coefficient can be determined by analysing a random group of individuals asked to perform a given motor test several times under the same conditions as would be applied during the final test [9]. Motor abilities should be assessed in motor tests with the assumption of the following estimated intervals of reliability (correlation) coefficients: 0.95-0.99: perfect reliability, 0.90-0.94: high reliability, 0.80-0.89: acceptable reliability, 0.70-0.79: very weak reliability, 0.60-0.69: doubtful reliability for individual assessments, acceptable for inter-group comparisons. In tests of motor abilities, a correlation coefficient of 0.70 is generally regarded as satisfactory [3].

Sex and age exert significant effects on the reliability of motor tests, which has been found to be lowest in seniors and children of pre-school and early-school age, most likely because both groups are characterized by mood swings and a short attention span [4, 10, 11]. Physical and mental disabilities are also a limiting factor [12]. Physical disabilities resulting from low levels of physical activity are often encountered in seniors older than 60 years. Disabilities are observed if the reduction in activity levels leads to changes in cardiorespiratory fitness, upper and lower body muscular strength, balance and power, all of which are important components of physical function [4]. Physical disabilities are also present in patients with advanced Parkinson's disease, who are characterized by fluctuations in motor function [12]. These fluctuations have to be controlled in order to create similar clinical conditions during the test and retest assessments. Accurate and reliable assessments of physical fitness are difficult to perform in seniors and patients with Parkinson's disease owing to their limited physical abilities, mood swings, changes in motivation and concentration that frequently result from the administration of drugs which disrupt motor function [13].

The reliability of a test can be improved through greater standardization of motor tasks, a higher number of repetitions (test-retest method), a higher number of evaluated subjects, improvement in abilities during the test, introduction of alternative tests, and improvement in the participants' motivation. In reliability assessments performed with the use of the test-retest method, special attention should also be given to the 'training trend' or the 'fatigue trend,' which was first observed by Denisiuk [14]. The cited author demonstrated that daily measurements of physical fitness levels, obtained over a period of 12 days, produced different results in the same individuals. The presence of a 'training trend' was confirmed in a study evaluating the scores of a 500-m rowing ergometer test [15], as well as when determining the reliability of the 3-minute Burpee Test [3] and the 8-s Skipping with Hand Clapping (SHC) test among university students [16]. The presence of a 'training trend,' which points to a gradual improvement in motor abilities due to repeated performance of the same tasks, should also be identified during reliability assessments involving the retest method. A 'training trend' can be diagnosed by analysing correlation coefficients and the significance of differences between group means in successive repetitions [3]. The results of motor tests can be considerably influenced by the participants' health, mental condition, fatigue, and motivation $[17,18]$.

Accurate and reliable tests for assessing the physical fitness of children are needed to verify the effectiveness of physical activity programs that are implemented around the world [19]. Effective programs should increase physical activity levels and, consequently, improve physical fitness. Selected physical activities contribute to the development of specific and often neglected motor abilities, such as speed abilities. Accurate, reliable, and objective motor tests have to be applied to verify the effectiveness of exercises targeting selected motor abilities [20]. This approach enables children to develop age-appropriate motor abilities that are required for healthy function in later stages of life [21]. Our knowledge about children's motor abilities, skills, strengths, needs, and motivation has to be expanded [22]. For this reason, the reliability of new measurement instruments as well as the existing methods of evaluating motor abilities needs to be validated [23]. The reliability of speed tests has been relatively poorly researched. Assessments of the type have been performed among girls and boys aged 11 years during the slalom test (speed) and the hurdle test (agility) [24], and among girls and boys aged 13 and 14 years during the $4 \times 10 \mathrm{~m}$ shuttle run test [5].

The aim of this study was to evaluate the reliability of the 8-s SHC test repeated 10 times at weekly intervals. The above research goal was pursued by determining:

1. the values of correlation coefficients between the results of each of the 10 trials of the 8-s SHC test;

2. the presence of significant differences between the results of successive trials (average number of claps) that would point to the occurrence of a 'training trend.'

\section{Material and methods}

\section{Participants}

The study was performed among 117 children, including 60 girls (mean age: $67.80 \pm 9.00$ months) and 57 boys (mean age: $71.76 \pm 6.43$ months) who attended 
3 kindergartens in Poland, Spain, and the Republic of Serbia. The subjects were selected by purposive sampling from the groups of oldest kindergarteners. The participants were volunteers who did not take any medication or nutritional supplements, were in good health, had no history of blood diseases or diseases affecting biochemical or biomechanical factors. All subjects resided permanently in large cities (Olsztyn, Malaga, Belgrade) and participated in physical education classes with an identical curriculum (with regard to the duration and type of physical exercise). The psychophysical development of all participants was assessed as normal by kindergarten educators. Differences in the physical activity levels of children participating in extracurricular sports could significantly distort the examined relationships; therefore, children performing additional sports as well as children dismissed from physical activity for medical reasons were excluded from the study.

\section{Measurements}

During a meeting with the children's parents, a survey questionnaire was applied to collect additional information about the participants' physical activity levels or limitations resulting from a medically certified illness. The parents were asked the following questions:

1. Is your child healthy, does your child take any medications (e.g. for hypertension) or supplements?

2. Can your child participate in all types of physical activities in the kindergarten without any limitations?

3. Does your child participate in additional physical activities outside of kindergarten?

The child was excluded from the study if the parents gave a negative answer to questions 1 and 2 or gave a positive answer to question 3. Anthropometric measurements were performed in accordance with the methods proposed by Martin and Saller [25], and the results were used to calculate the body mass index (BMI), which is generally regarded as a relevant and reliable statistic for evaluating excessive weight and obesity, also in children [26].

The children's speed abilities were evaluated during the 8-s SHC test (Figure 1). The original 10-s version of the test was developed for the Zuchora Physical Fitness Index [27]. To introduce more rigorous evaluation standards for the test, the time of each trial was shortened to 8 seconds, which facilitated the counting of claps that were performed correctly under the knee. All participants performed the motor test 10 times at weekly intervals (retest method). During each trial, the children performed the task twice, and the better result was recorded. Anthropometric measurements did not reveal contraindications for applying the 8-s SHC test in any of the evaluated children. The phases of the 8-s SHC, presented in Figure 1, were as follows:

- Phase 1: The participant stood in neutral position (Figure 1a).

- Phase 2: When cued to start the trial, the participant ran in place and lifted the knees high (with thighs at least parallel to the ground), while clapping hands under the bent knee (Figure $1 \mathrm{~b}$ and $\mathrm{c}$ ).

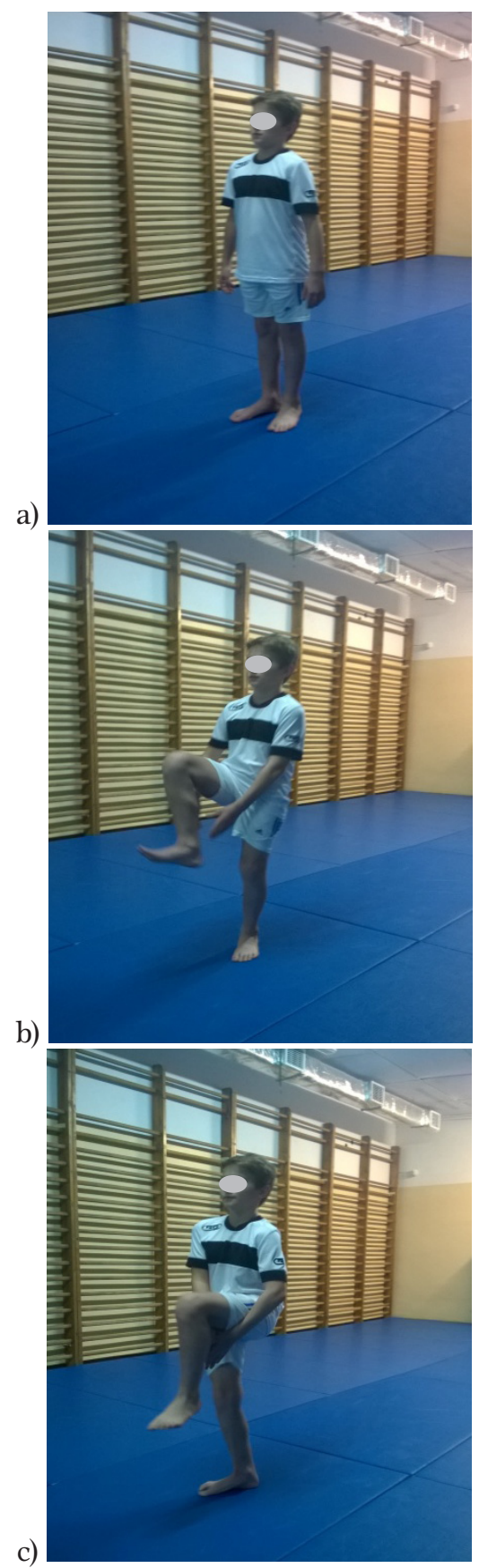

Figure 1. The phases of the 8-s Skipping with Hand Clapping test 
The score was the number of claps performed in 8 seconds.

Importantly, the participants were not allowed to slouch during the test. The torso was to stay erect, and the child had to clap their hands against each other and not against the raised leg. The errors that disqualified the participants, presented in Figure 2, were the following: torso leaning forward (Figure 2a), the child slouching and clapping the leg (Figure 2b), the leg not raised high enough (Figure 2c).

a)

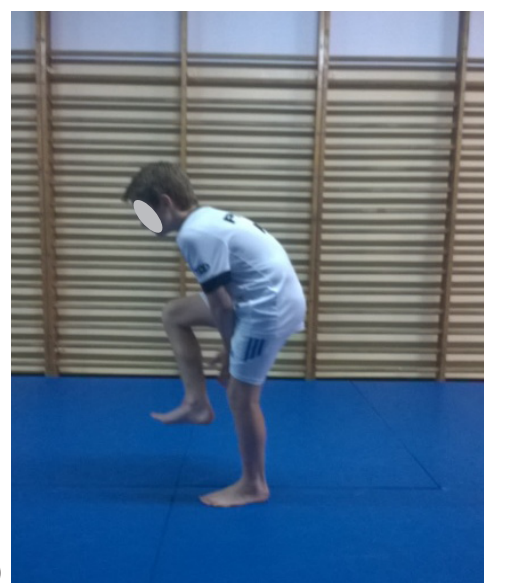

b)

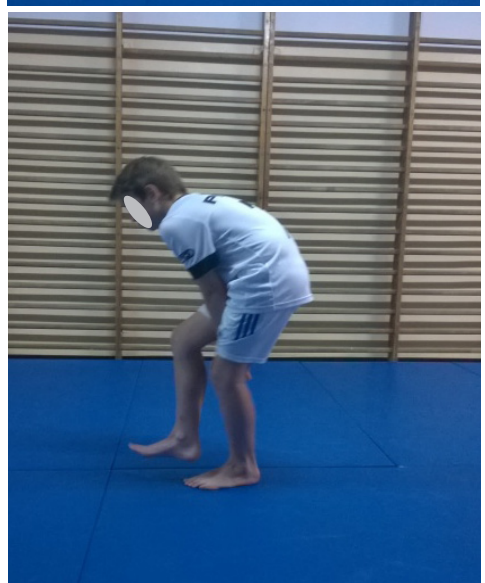

c)

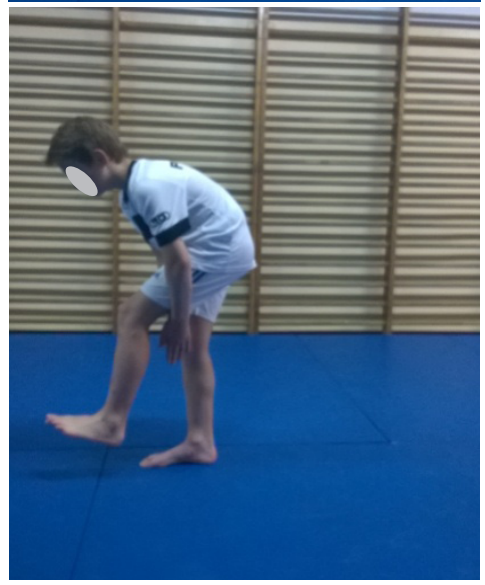

Figure 2. The most common errors made during the 8-s Skipping with Hand Clapping test
All anthropometric measurements and the 8-s SHC test were conducted in the gym facilities of kindergartens. Early education teachers working with the evaluated children assisted the researchers in the measurement process. The teachers' support was elicited because earlier observations revealed that children felt more comfortable and relaxed in their presence. During a meeting held before the study, the teachers were instructed how to perform the exercise properly and safely. The children were instructed how to perform the 8-s SHC test correctly, and they were able to improve their technique 3 times during 3 meetings preceding the study (the total of 9 trials). Before the test, the participants took part in a 5-minute warmup routine. The warm-up routine was identical in all groups, and it comprised selected physical exercises and movement patterns, including jogging, wrist, elbow and arm circles, leg swings, jumps, balance exercises, front hold exercises, 2 8-m dashes, dynamic stretching, and corrective drills [28]. The warm-up routine was identical throughout each trial during the 10 -week period.

\section{Statistical analysis}

The measurements of body mass, body height, BMI, and the number of claps were averaged, and standard deviation was computed with the use of descriptive statistics. Maximum and minimum values, the median, and the coefficient of variation were also determined. Correlation coefficients were calculated to determine the statistical significance of the correlations between the dependent variable (number of claps) and the independent variable (successive trial) in view of grouping factors.

The researchers also established whether successive trials (independent variables) of the 8-s SHC test, performed at weekly intervals, significantly influenced the average number of claps (dependent variable) in a given trial, which would suggest the presence of a 'training trend.' The dependent variable (number of claps) was processed by analysis of variance (ANOVA). Depending on whether the conditions for the application of the test were fulfilled, the repeated measures ANOVA (parametric test) or the Friedman non-parametric test were performed. If statistically significant differences were found, Conover-Iman's post-hoc test was additionally used to identify the trials of the 8-s SHC test that differed significantly in the number of claps, which could testify to the presence of a 'training trend.' Calculations were performed at the significance level of $\alpha=0.05$ in the Statistica v. 10 software package. 


\section{Ethical approval}

The research related to human use has been complied with all the relevant national regulations and institutional policies, has followed the tenets of the Declaration of Helsinki, and has been approved by the Bioethical Committee and the authorities of the University of Warmia and Mazury in Olsztyn, Poland.

\section{Informed consent}

The kindergarten principals notified the parents of the participants about the purpose of the study. Informed consent has been obtained from the kindergarten principals and the parents of all individuals included in this study.

\section{Results}

The statistical characteristics of the evaluated girls and boys are presented in Table 1 . The results of the correlation analysis were used to calculate correlation coefficients between the numbers of claps in successive trials of the 8-s SHC test (Table 2).

The mean body height and body weight were determined as $117.30 \pm 7.89 \mathrm{~cm}$ and $21.64 \pm 3.91 \mathrm{~kg}$ in girls and $122.76 \pm 6.45 \mathrm{~cm}$ and $25.16 \pm 2.90 \mathrm{~kg}$ in boys, respectively. The mean BMI values were within the norm in both girls $\left(15.68 \pm 2.12 \mathrm{~kg} / \mathrm{m}^{2}\right)$ and boys $\left(16.69 \pm 1.49 \mathrm{~kg} / \mathrm{m}^{2}\right)$.

On the basis of the previously cited method for evaluating the reliability of motor ability tests [7], the values of correlation coefficients between successive trials of the 8-s SHC test performed by girls and boys ranged from acceptable reliability $(0.80-0.90)$ to perfect reliability (0.95-0.99) (Table 2).

The presence of statistically significant differences in the numbers of claps in successive test trials could not be determined with the use of the values of correlation coefficients. Additional analyses were performed to establish the significance of differences between the average numbers of claps in successive

Table 1. Statistical characteristics of the girls and boys included in the study

\begin{tabular}{lrcccrr}
\hline Parameter & $\bar{x}$ & $S D$ & Maximum & Minimum & Median & $C V(\%)$ \\
\hline Girls $(n=60)$ & & & & & & \\
Body mass $(\mathrm{kg})$ & 21.64 & 3.91 & 31.00 & 14.00 & 22.00 & 18.05 \\
Body height $(\mathrm{cm})$ & 117.30 & 7.89 & 136.50 & 102.50 & 116.75 & 6.73 \\
BMI $\left(\mathrm{kg} / \mathrm{m}^{2}\right)$ & 15.68 & 2.12 & 22.32 & 11.77 & 17.30 & 13.50 \\
Number of claps & 16.38 & 3.86 & 28 & 6 & 16 & 23.55 \\
\hline Boys $(n=57)$ & & & & & & \\
Body mass $(\mathrm{kg})$ & 25.16 & 2.90 & 32.00 & 20.00 & 25.00 & 11.53 \\
Body height $(\mathrm{cm})$ & 122.76 & 6.45 & 139.00 & 112.00 & 124.00 & 5.25 \\
BMI $\left(\mathrm{kg} / \mathrm{m}^{2}\right)$ & 16.69 & 1.49 & 19.07 & 13.46 & 16.91 & 8.82 \\
Number of claps & 18.77 & 2.76 & 26 & 12 & 19 & 14.69 \\
\hline
\end{tabular}

$\bar{x}$ - mean value, $S D$ - standard deviation, $C V$ - coefficient of variation

Table 2. Correlation coefficients between successive test trials performed by girls $(n=60)$ and boys $(n=57)$

\begin{tabular}{|c|c|c|c|c|c|c|c|c|c|c|}
\hline \multirow[b]{2}{*}{ Boys } & \multicolumn{10}{|c|}{ Correlation coefficients between successive test trials } \\
\hline & 1 & 2 & 3 & 4 & 5 & 6 & 7 & 8 & 9 & 10 \\
\hline 1 & & 0.8349 & 0.8344 & 0.8750 & 0.8775 & 0.8417 & 0.8564 & 0.8928 & 0.8794 & 0.8883 \\
\hline 2 & 0.9038 & & 0.9264 & 0.9451 & 0.9107 & 0.9115 & 0.8973 & 0.9083 & 0.9270 & 0.9153 \\
\hline 3 & 0.9388 & 0.9440 & & 0.9383 & 0.9456 & 0.9472 & 0.9274 & 0.9499 & 0.9529 & 0.9607 \\
\hline 4 & 0.9340 & 0.9591 & 0.9699 & & 0.9453 & 0.9320 & 0.9523 & 0.9552 & 0.9632 & 0.9618 \\
\hline 5 & 0.9200 & 0.9568 & 0.9612 & 0.9734 & & 0.9588 & 0.9636 & 0.9682 & 0.9733 & 0.9758 \\
\hline 6 & 0.9376 & 0.9467 & 0.9422 & 0.9632 & 0.9731 & & 0.9540 & 0.9620 & 0.9701 & 0.9735 \\
\hline 7 & 0.9132 & 0.9498 & 0.9405 & 0.9677 & 0.9784 & 0.9604 & & 0.9707 & 0.9786 & 0.9765 \\
\hline 8 & 0.9260 & 0.9450 & 0.9429 & 0.9747 & 0.9790 & 0.9702 & 0.9753 & & 0.9831 & 0.9873 \\
\hline 9 & 0.9310 & 0.9539 & 0.9482 & 0.9780 & 0.9793 & 0.9791 & 0.9821 & 0.9846 & & 0.9868 \\
\hline 10 & 0.9301 & 0.9634 & 0.9510 & 0.9684 & 0.9753 & 0.9795 & 0.9832 & 0.9779 & 0.9834 & \\
\hline
\end{tabular}

Values in bold denote statistically significant correlations, values in italics denote girls. 


\section{HUMAN MOVEMENT}

R. Podstawski et al., Reliability of the 8-s SHC test

trials. The applicability of parametric and non-parametric tests had to be verified before they were used in calculations (to determine if the measured parameters had normal distribution, homogeneity of variance). The measured parameter (number of claps) in successive trials did not have normal distribution (Shapiro-Wilk test, $p>0.05$ ); therefore, the research hypothesis was verified with the use of the Friedman test, the non-parametric alternative to analysis of variance with repeated measurements of dependent variables. The mean number of claps in successive test trials for different grouping variables ('Girls' and 'Boys') are compared in Table 3.

The results of the Friedman test revealed statistically significant differences between the average numbers of claps in successive test trials $(p<0.05)$. Conover-Iman's post-hoc test was used to identify the trials of the 8-s SHC test that differed significantly in the number of claps. The results are presented in Table 4 .
The results indicate that the reliability of the test was determined by the participants' sex. In girls, statistically significant differences in the numbers of claps were observed up to the $5^{\text {th }}$ trial, and in boys - up to the $3^{\text {rd }}$ trial (with 2 repetitions per trial) (Table 4 ).

\section{Discussion}

The study, conducted in line with the procedural algorithm, produced interesting observations. Statistically significant differences in the average number of claps were noted up to the $5^{\text {th }}$ trial in girls and up to the $3^{\text {rd }}$ trial in boys. It should be noted, however, that the participants performed the test twice in each week of the study and 9 times in the 3 weeks preceding the final test (3 times during each of the 3 meetings). Therefore, girls performed the motor task 19 times ( 9 before the final test and $5 \times 2$ during the study) and boys -15 times ( 9 before the final test and $3 \times 2$ during the study).

Table 3. A comparison of the average numbers of claps in successive trials of the 8-s SHC test: girls and boys

Girls

Friedman ANOVA and Kendall's coefficient of concordance, chi-squared, ANOVA (girls, $n=60, d f=9$ ): 73.4459 , $p<0.05$; coefficient of concordance: 0.1360 , average rank $r=0.1214$

\begin{tabular}{|c|c|c|}
\hline Trial & Average rank & Sum of ranks \\
\hline 1 & 4.61 & 277.00 \\
\hline 2 & 3.86 & 232.00 \\
\hline 3 & 4.50 & 270.50 \\
\hline 4 & 4.96 & 298.00 \\
\hline 5 & 5.06 & 304.00 \\
\hline 6 & 6.35 & 381.50 \\
\hline 7 & 6.20 & 372.00 \\
\hline 8 & 6.55 & 393.50 \\
\hline 9 & 6.26 & 376.00 \\
\hline 10 & 6.59 & 395.50 \\
\hline \multicolumn{3}{|c|}{ Boys } \\
\hline \multicolumn{3}{|c|}{$\begin{array}{l}\text { Friedman ANOVA and Kendall's coefficient of concordance, chi-squared, ANOVA (boys, } n=57, d f=9 \text { ): 39.0909, } \\
\qquad p<0.05 \text {; coefficient of concordance: } 0.0762 \text {, average rank } r=0.0597\end{array}$} \\
\hline Trial & Average rank & Sum of ranks \\
\hline 1 & 4.38 & 250.00 \\
\hline 2 & 4.28 & 244.50 \\
\hline 3 & 5.16 & 294.00 \\
\hline 4 & 5.19 & 296.00 \\
\hline 5 & 5.63 & 321.00 \\
\hline 6 & 5.58 & 318.50 \\
\hline 7 & 6.08 & 347.00 \\
\hline 8 & 5.94 & 339.00 \\
\hline 9 & 6.25 & 356.50 \\
\hline 10 & 6.46 & 368.50 \\
\hline
\end{tabular}


Table 4. The results of Conover-Iman's post-hoc test indicating differences in the average number of claps performed by girls $(n=60)$ and boys $(n=57)$ in successive trials

\begin{tabular}{|c|c|c|c|c|c|c|c|c|c|c|}
\hline Gir & & & nngyer_Im & an's test: & imated $\mathrm{p}$ & bability va & lues for po & st-hoc tests & & \\
\hline Boys & 1 & 2 & 3 & 4 & 5 & 6 & 7 & 8 & 9 & 10 \\
\hline 1 & & 0.370482 & 0.179152 & 0.039488 & 0.003976 & 0.000006 & 0.000004 & 0.000001 & 0.000004 & 0.000005 \\
\hline 2 & 0.876790 & & 0.032946 & 0.003976 & 0.000185 & 0.000004 & 0.000005 & 0.000001 & 0.000004 & 0.000001 \\
\hline 3 & 0.026506 & 0.029954 & & 0.411678 & 0.104980 & 0.000649 & 0.000160 & 0.000018 & 0.000185 & 0.000021 \\
\hline 4 & 0.004465 & 0.005765 & 0.485340 & & 0.370482 & 0.007977 & 0.002924 & 0.000451 & 0.003120 & 0.000525 \\
\hline 5 & 0.000345 & 0.000516 & 0.165702 & 0.438183 & & 0.062070 & 0.032692 & 0.008549 & 0.032946 & 0.009354 \\
\hline 6 & 0.000298 & 0.000466 & 0.159978 & 0.425618 & 0.938210 & & 0.676553 & 0.362105 & 0.709040 & 0.384149 \\
\hline 7 & 0.000050 & 0.000084 & 0.071982 & 0.234489 & 0.612972 & 0.641815 & & 0.577736 & 0.940513 & 0.601375 \\
\hline 8 & 0.000030 & 0.000050 & 0.056286 & 0.195021 & 0.532743 & 0.563010 & 0.876790 & & 0.548256 & 0.940513 \\
\hline 9 & 0.000014 & 0.000022 & 0.035897 & 0.139421 & 0.417939 & 0.445000 & 0.718078 & 0.816103 & & 0.577736 \\
\hline 10 & 0.000004 & 0.000006 & 0.017841 & 0.082769 & 0.287933 & 0.309417 & 0.532743 & 0.612972 & 0.756486 & \\
\hline
\end{tabular}

Values in bold denote statistically significant correlations, values in italics denote girls.

Specific abilities, such as speed abilities, should be evaluated in view of individual predispositions and the associations with motor skills which expose those abilities [29]. A shorter 'training trend' among boys could indicate that boys more quickly assimilate the spatiotemporal structure of speed tests which measure the maximum frequency of movements. It could also be attributed to boys' relatively higher motor abilities and broader range of motor skills in comparison with girls [30-32]. The evaluation of the reliability of the 8-s SHC test among university students (women and men) revealed the presence of a 'training trend' up to the $5^{\text {th }}$ repetition [16]. The number of repetitions required to eliminate the 'training trend' was lower in the group of university students. The vast majority of them were 18-25-year-olds, and therefore they were characterized by the highest level of physical fitness. The development and maturation of the central and peripheral nervous systems, whose proper function is required to develop speed and coordination abilities, are already completed in this age group. The processes of excitation and inhibition are in relative equilibrium in 18-25-year-olds, unlike in kindergarteners aged 5 and 6 years. From the methodological point of view, the obtained results indicate that kindergarteners require a relatively high number of repetitions to reliably perform the 8-s SHC test. Children need longer preparation for physical fitness tests than adults. Children are also more emotionally labile than adults and thus physical fitness tests should be carried out in a friendly and familiar environment.

The presence of a 'training trend' was also reported in a study in which female and male university students rowed the distance of $500 \mathrm{~m}$ on an ergometer.
Female subjects continued to improve their results up to the $4^{\text {th }}$ repetition [15]. In an evaluation of the reliability the 3-minute Burpee Test, relative stability of the results was achieved after the $5^{\text {th }}$ repetition in both male and female students [3]. The duration of a motor task significantly influences the reliability of the test. In relatively long tasks, such as endurance running, the error of measurement is compensated by other factors (such as cardiovascular endurance), which improves reliability. Most speed and coordination tests are very short, which prevents error compensation $[5,9]$.

The reliability of a motor test can also be evaluated with the use of the parallel-test method, which analyses the correlations with another test for assessing the same motor ability. In this study of kindergarteners, the results of the 8-s SHC test were significantly positively correlated with tests for evaluating various motor abilities, including speed: $4 \times 10 \mathrm{~m}$ shuttle run $(+0.73)$, dynamic strength of lower limbs: standing long jump (+0.58), and abdominal strength: sit-ups for 30 seconds (+0.62) [27]. The above suggests that the evaluated test has a more hybrid character.

\section{Practical applications and limitations}

The 8-s SHC test is easy and cheap to conduct even under difficult conditions. On the basis of the reliability intervals and a comparison of correlation coefficients between successive trials of the test in our study, we were able to demonstrate that the 8-s SHC test ranged between acceptable (0.80-0.89) and high (0.90-0.94) or even perfect (0.95-0.99) reliability. It should be noted, however, that reliability is a necessary, but not the only prerequisite of validity. An unreliable 
test is never valid, whereas a reliable test does not always meet the validity criterion. In view of the above, the 8-s SHC test should be further investigated to determine its validity and to develop classification criteria for various developmental stages based on representative samples.

Mynarski [33] studied the structure of motor abilities in children and adolescents aged $8-18$ years and demonstrated that the 10-s SHC test measured the maximum frequency of movements, which was particularly visible among girls. The frequency of wholebody movements (in addition to motor speed, explosive strength, and agility) is evaluated in fitness tests that rely on anaerobic sources of energy and measure the maximal anaerobic capacity (threshold) [29]. Coordination abilities, such as dynamic-spatial differentiation and balance, also play an important role in this motor task [33].

The results of this study indicate that other motor tests should be analysed for the presence of a 'training trend' and the minimum number of repetitions which are required to master the exercise (no statistically significant differences between the results). Unverified tests could produce unreliable results because the tested subjects continue to learn with every repetition. Test trials should be conducted at planned intervals to prevent the participants from improving their motor abilities. For this reason, trials were held at weekly intervals in our study.

\section{Conclusions}

1. The 8-s SHC test is reliable and appropriate for kindergarteners. The values of correlation coefficients for the 8-s SHC test were determined in the range of acceptable to perfect reliability for both girls and boys.

2 . The results of the study were processed statistically to reveal significant differences between the numbers of claps performed by girls and boys in successive trials of the 8-s SHC test, which point to the presence of a 'training trend' (up to the $3^{\text {rd }}$ trial in boys and up to the $5^{\text {th }}$ trial in girls). In the 8-s SHC test, the speed abilities of kindergarteners can be reliably evaluated after the 'training trend' has been eliminated. A minimum number of repetitions, estimated as 19 in girls and 15 in boys, have to be performed in advance for the final test to deliver reliable results.

\section{Acknowledgments}

The authors would like to thank all the children who volunteered for the study.

\section{Disclosure statement}

No author has any financial interest or received any financial benefit from this research.

\section{Conflict of interest}

The authors state no conflict of interest.

\section{References}

1. Pilicz S. The measurement of the general physical fitness [in Polish]. Studia i Monografie, 65. Warszawa: AWF; 1997.

2. Rikli RE, Jones CJ. Assessing physical performance in independent older adults: issues and guidelines. $\mathrm{J}$ Aging Phys Act. 1997;5(3):244-261; doi: 10.1123/japa. 5.3.244.

3. Podstawski R, Markowski P, Choszcz D, Klimczak J, Romero Ramos O, Merino Marban R. Methodological aspect of evaluation of the reliability the 3-Minute Burpee Test. Arch Budo Sci Martial Art Extreme Sport. 2016;12(1):137-144.

4. Ritchie C, Trost SG, Brown W, Armit C. Reliability and validity of physical fitness field tests for adults aged 55 to 70 years. J Sci Med Sport. 2005;8(1):61-70; doi: 10.1016/S1440-2440(05)80025-8.

5. Ortega FB, Artero EG, Ruiz JR, Vincente-Rodriguez G, Bergman P, Hagströmer M, et al. Reliability of healthrelated physical fitness tests in European adolescents. The HELENA study. Int J Obes. 2008;32 Suppl 5: S49-S57; doi: 10.1038/ijo.2008.183.

6. Bruton A, Conway JH, Holgate ST. Reliability: what is it, and how is itmeasured? Physiotherapy. 2000;86(2):9499; doi: 10.1016/S0031-9406(05)61211-4.

7. Morris DM, Uswatte G, Crago JE, Cook EW, Taub E. The reliability of the Wolf Motor Function Test for assessing upper extremity function after stroke. Arch Phys Med Rehabil. 2001;82(6):750-755; doi: 10.1053/ apmr.2001.23183.

8. Platz T, Pinkowski C, van Wijck F, Kim IH, di Bella P, Johnson G. Reliability and validity of arm function assessment with standardized guidelines for the FuglMeyer Test, Action Research Arm Test and Box and Block Test: a multicentre study. Clin Rehabil. 2005;19(4): 404-411; doi: 10.1191/0269215505cr832oa.

9. Atkinson G, Nevill AM. Statistical methods for assessing measurement error (reliability) in variables relevant to sports medicine. Sports Med. 1998;26(4):217238; doi: 10.2165/00007256-199826040-00002.

10. Krombholz H. Physical performance in relation to age, sex, social class and sports activities in kindergarten and elementary school. Percept Motor Skills. 1997;84(3 Pt 2):1168-1170; doi: 10.2466/pms.1997.84.3c.1168.

11. Molenaar HM, Zuidam JM, Selles RW, Stam HJ, Hovius SE. Age-specific reliability of two grip-strength dynamometers when used by children. J Bone Joint Surg Am. 2008;90(5):1053-1059; doi: 10.2106/JBJS.G.00469. 
12. Metman LV, Myre B, Verwey, Hassin-Baer S, Arzbaecher J, Sierens D, et al. Test-retest reliability of UPDRSIII, dyskinesia scales, and timed motor test in patients with advanced Parkinson's disease: an argument against multiple baseline assessments. Mov Disord. 2004;19(9):1079-1084; doi: 10.1002/mds.20101.

13. Van Hilten JJ, van der Zwan AD, Zwinderman $\mathrm{AH}$, Roos RA. Rating impairment and disability in Parkinson's disease: evaluation of the Unified Parkinson's Disease Rating Scale. Mov Disord. 1994;9(1):84-88; doi: $10.1002 / \mathrm{mds} .870090113$.

14. Denisiuk L. Analyses of the results of selected physical fitness tests [in Polish]. Wych Fiz Sport. 1961;3:327-363.

15. Podstawski R, Choszcz D, Konopka S. The impact of training on the $500 \mathrm{~m}$ rowing ergometer time and the assessment of the applied test's relevancy. Hum Mov. 2011;12(3):264-272; doi: 10.2478/v10038-011-0029-3.

16. Podstawski R, Markowski P, Choszcz D, Merino-Marbán R, Romero-Ramos O, Curtolo C. An evaluation of the reliability of the 8-second Skipping with Hand Clapping (8-s SHC) test with the use of the retest method. Trends Sport Sci. 2017;4(24):143-150; doi: 10:23829/ TSS.2017.24.4-1.

17. Pires Ferraz RM, van den Tillaar R, Pereira A, Marques $\mathrm{MC}$. The effect of fatigue and duration knowledge of exercise on kicking performance in soccer players. J SportHealthSci.2016; doi:10.1016/j.jshs.2016.02.001.

18. Moore RD, Romine MW, O'connor PJ, Tomporowski PD. The influence of exercise-induced fatigue on cognitive function. J Sports Sci. 2012;30(9):841-850; doi: 10.1080/02640414.2012.675083.

19. Sanders SW. Active for life: developmentally appropriate movement programs for young children. Washington: National Association for the Education of Young Children; 2002.

20. Kroes M, Vissers YLJ, Sleijpen FAM, Feron FJM, Kessels AGH, Bakker E, et al. Reliability and validity of a qualitative and quantitative motor test for 5- to 6-year-old children. Eur J Paediatr Neurol. 2004;8(3): 135-143; doi: 10.1016/j.ejpn.2004.01.007.

21. Hraski M, Horvat V, Horvat I. Reliability of instrument for assessing standing long jump performance in preschool children. In: Milanović D, Sporiš G (eds.), Integrative power of kinesiology. Zagreb: University of Zagreb Press; 2011; 235-237.

22. Hands B, Martin M. Fundamental movement skills: children's perspectives. Aust J Early Child. 2003;28(4): 47-51.

23. Zuvela F, Bozanic A, Miletic D. POLYGON - a new fundamental movement skills test for 8 year old children: construction and validation. J Sports Sci Med. 2011; 10(1):157-163.

24. Alricsson M, Harms-Ringdahl K, Werner S. Reliability of sports related functional tests with emphasis on speed and agility in young athletes. Scan J Med Sci Sports. 2001;11(4):229-232; doi: 10.1034/j.1600-0838.2001. 110406.x.
25. Martin R, Saller K. Textbook of anthropology [in German]. Stuttgart: Fischer; 1957.

26. Cole TJ, Felgal KM, Nicholls D, Jackson AA. Body mass index cut offs to define thinness in children and adolescents: international survey. Br Med J. 2007; 335(7612):194-197;doi:10.1136/bmj.39238.399444.55.

27. Podstawski R, Konopka S, Mańkowski S, Choszcz D, Borysławski K. Correlations between anthropometric characteristics, heart rate and the results of the 8-second skipping with hand clapping (SHC) test in preschool children. Trends Sport Sci. 2016;23(1):25-31.

28. Frandkin AJ, Zazryn TR, Smoliga JM. Effects of warming-up on physical performance: a systematic review with meta-analysis. J Strength Cond Res. 2010;24(1): 140-148; doi: 10.1519/JSC.0b013e3181c643a0.

29. Szopa J, Chwała W, Ruchlewicz T. Investigations on structure of 'energetic' motor abilities and validity of their testing [in Polish]. Antropomotoryka. 1998;18(17): 3-41.

30. Bénéfice E, Fouére T, Malina RM. Early nutritional history and motor performance of Senegalese children, 4-6 years of age. Ann Hum Biol. 1999;26(5):443-455; doi: 10.1080/030144699282561.

31. Milanese C, Bortolami O, Bertucco M, Verlato G, Zancanaro C. Anthropometry and motor fitness in children 6-12 years. J Hum Sport Exerc. 2010;5(2):265279; doi: 10.4100/jhse.2010.52.14.

32. Podstawski R, Borysławski K. Relationships between selected anthropometric features and motor abilities of children aged 7-9. Clin Kinesiol. 2012;66(4):82-90.

33. Mynarski W. Internal structure of motor abilities in children and adolescents aged 8 to 18 years [in Polish]. In: Raczek J (ed.), Studies on human motor skills [in Polish]. Katowice: AWF; 2000; 9-34. 